\title{
FORMULATION AND EVALUATION OF SUSTAINED RELEASE MATRIX TABLETS OF LEVOSULPIRIDE USING NATURAL POLYMER
}

\author{
SHANMUGAM S ${ }^{1}$, BABU R ${ }^{2 *}$, SATHEESHKUMAR ${ }^{2}$, SHANMUGASUNDARAM P² \\ ${ }^{1}$ Department of Pharmaceutics, Adhiparasakthi College of Pharmacy, Melmaruvathur, Tamil Nadu, India. ${ }^{2}$ Department of Pharmaceutics, \\ Vels Institute of Science Technology and Advanced Studies, Vels University, Pallavaram, Chennai, Tamil Nadu, India. \\ Email: shanmugam.saravanabhavan@yahoo.com \\ Received: 03 February 2017, Revised and Accepted: 25 February 2017
}

ABSTRACT

Objective: The objective of the present study was to develop sustained release (SR) matrix tablets of levosulpiride using natural polymers.

Methods: The tablets were prepared with different ratios of chitosan, xanthan gum, and guar gum by wet granulation technique. The solubility study of the levosulpiride was conducted to select a suitable dissolution media for in vitro drug release studies.

Results: Fourier transform infrared (IR) study revealed no considerable changes in IR peak of levosulpiride and hence no interaction between drug and the excipients. Differential scanning calorimetry thermograms showed that no drug interaction occurred during the manufacturing process. In vitro dissolution study was carried out for all the formulation and the results compared with marketed SR tablet. In vitro release from the formulation LF3 was found to be $94.53 \%$. Hardness of LF3 was found to be $7.96 \pm 0.06 \mathrm{~kg} / \mathrm{cm}^{2}$. Higher hardness tablets contain a compact mass of polymer with relatively less pore, resulting in slower release. The drug release from matrix tablets was found to decrease with increase in polymer ratio of chitosan, xanthan gum, and guar gum.

Conclusion: Formulation LF3 exhibited almost similar drug release profile in dissolution media as that of marketed tablets. From the results of dissolution data fitted to various drug release kinetic equations, it was observed that highest correlation was found for first order, Higuchi's and Korsmeyer equation, which indicate that the drug release occurred through diffusion mechanism.

Keywords: Levosulpiride, Sustained release tablets, Natural polymers, In vitro drug release studies.

(C) 2017 The Authors. Published by Innovare Academic Sciences Pvt Ltd. This is an open access article under the CC BY license (http://creativecommons. org/licenses/by/4. 0/) DOI: http://dx.doi.org/10.22159/ajpcr.2017.v10i5.17475

\section{INTRODUCTION}

In the recent years, sustained release (SR) drug delivery systems are gaining more interest as these systems deliver the drug continuously for prolonged period to maintain the steady state blood level concentration, therefore providing reduction in the dosing frequency and increasing better patient compliance. These systems are designed mainly for the drugs which are required to be taken frequently [1].

These SR drug delivery systems are prepared using natural or synthetic or semi-synthetic polymers. They offer many advantages such as enhanced bioavailability, site-specific drug delivery, SR of drug over longer period, retention of formulation in entire length of gastrointestinal tract, release of desired concentration of drug at targeted site, and improved patient compliance due to reduction in frequent dosing [2].

Since levosulpiride requires frequent dosing to maintain therapeutic drug concentration, it was chosen as an ideal candidate for SR dosage form. Matrix tablets are prepared either wet granulation/direct compression method. The study is conducted to design and evaluate the SR tablets of levosulpiride [3,4] with natural polymers such as chitosan, xanthan gum, and guar gum.

Chitosan, xanthan gum, and guar gum were selected for this study based on its non-toxic nature, easy compression, swelling properties, and accommodation to high level of drug loading [5].

The objective of the present study is to develop an SR tablet of levosulpiride which release the drug in a sustained manner over a period of $12 \mathrm{hrs}$, using different natural polymers and study on polymer concentration effect on release pattern.

\section{MATERIALS AND METHODS}

Materials

Levosulpiride was obtained as a gift sample from Sunglow Pharmaceuticals, Puducherry. Chitosan, xanthan gum, and guar gum were purchased from Sigma Aldrich. Microcrystalline cellulose, polyvinylpyrrolidone, and magnesium stearate were purchased from Chemika-Biochemika-Reagents, Mumbai, Maharashtra, India. All other chemicals and reagents used for these studies were of analytical grade.

\section{Methods}

\section{Formulation of levosulpiride SR tablets}

The levosulpiride SR tablets were prepared by wet granulation technique [6]. Composition of SR tablets of levosulpiride is given in (Table 1) Levosulpiride was passed through sieve \# 40. The releaseretarding polymers, namely, chitosan, xanthan gum, and guar gum and additive microcrystalline cellulose and magnesium stearate as glidants, were passed through sieve \# 60. Polyvinylpyrrolidone and isopropyl alcohol was used as granulating agent to get coherent mass. The wet granules were dried at room temperature. The dried granules were passed through sieve no \# 14. Mixed with magnesium stearate and compressed into tablets on a 16 station Rotary Cadmach Machine.

\section{Drug excipient compatibility studies}

Infrared (IR) spectroscopy

IR spectroscopy was conducted using a Shimadzu Fourier transform IR 8300 spectrophotometer, and the spectrum was recorded in the wavelength region 4000-400/cm [7]. 
Differential scanning calorimetry (DSC)

DSC (Shimadzu DSC-60, Japan)was used to examine the thermal behavior of pure drug and drug-additive mixtures. DSC thermograms of individual levosulpiride and 1:1 drug-excipient physical mixtures were compared.

\section{Precompression parameters}

Angle of repose

Angle of repose was determined using fixed funnel method. The blend was poured through a funnel that can be raised vertically until a maximum cone height $(\mathrm{h})$ was obtained. Radius of the heap $(\mathrm{r})$ was measured, and angle of repose was calculated using formula [7]

$\theta=\tan -1(\mathrm{~h} / \mathrm{r})$

where $\theta$ is angle of repose, $\mathrm{h}$ is height of pile, and $\mathrm{r}$ is the radius of the base pile.

\section{Loose bulk density (LBD)}

Apparent LBD was determined by pouring blend into a graduated cylinder. The bulk volume $\left(\mathrm{V}_{\mathrm{o}}\right)$ and weight of powder (M) were determined. The LBD was calculated using the formula [8]:

$\mathrm{LBD}=$ Weight of the powder $(\mathrm{M}) /$ volume of the packing $\left(\mathrm{V}_{\mathrm{o}}\right)$

\section{Tapped bulk density (TBD)}

The measuring cylinder containing known mass of blend was tapped for a fixed time. The minimum volume ( $\mathrm{V}_{\mathrm{t}}$ ) occupied in the cylinder and weight of powder blend (M) as measured. The TBD was calculated using the formula [7]:

TBD=Weight of the powder (M)/tapped volume of the packing (Vt)

\section{Carr's compressibility index}

The simplex way of measurement of the free flow of powder is compressibility, an indication of the ease with which a material can be induced to flow is given by compressibility index of the granules was determined by Carr's compressibility index (C) which is calculated using the following formula [9]:

$\mathrm{C}=[(\mathrm{TBD}-\mathrm{LBDTB})] \times 100$

\section{Hausner ratio}

Hausner ratio is an indirect index of ease of powder flow. It is calculated by the following formula [9]:

Hausner's ratio=Tapped bulk density (TBD)/ Loose bulk density (LBD)

where TBD is tapped bulk density and LBD is loose bulk density. Lower Hausner ratio $(<1.25)$ indicates better flow properties than higher ones $(>1.25)$.

\section{Post compression parameters}

All 9 batches of tablets were evaluated for various parameters such as weight variation, friability, hardness, drug content, disintegration, and dissolution, and results are reported in Table 3.

\section{Uniformity of weight}

This test is performed to maintain the uniformity of weight of each tablet which should be in the prescribed range, this is done by sampling and weighing 20 tablets at random and average weight is calculated. Not more than two of the individual weights deviate from the average weight by more than the percentage show in Table 3 , and none deviate by more than twice the percentage. The mean and standard deviation were determined [7].

\section{Thickness}

The thickness and diameter of the tablets were determined using a micrometer screw gauge. Totally, 5 tablets from each type of formulation were used and average values were calculated. It is expressed in $\mathrm{mm}[7,9]$.

Table 1: Preparation of levosulpiride SR tablets LF1-LF9

\begin{tabular}{|c|c|c|c|c|c|c|c|c|c|c|}
\hline \multirow[t]{2}{*}{ S. No } & \multirow[t]{2}{*}{ Ingredients (mg) } & \multicolumn{9}{|c|}{ Formulation code } \\
\hline & & LF1 & LF2 & LF3 & LF4 & LF5 & LF6 & LF7 & LF8 & LF9 \\
\hline 1 & Levosulpiride & 75 & 75 & 75 & 75 & 75 & 75 & 75 & 75 & 75 \\
\hline 2 & Chitosan & 25 & 50 & 75 & - & - & - & - & - & - \\
\hline 3 & Xanthan gum & - & - & - & 25 & 50 & 75 & - & - & - \\
\hline 4 & Guar gum & - & - & - & - & - & - & 25 & 50 & 75 \\
\hline 5 & MCC & 93.2 & 68.2 & 43.2 & 93.2 & 68.2 & 43.2 & 93.2 & 68.2 & 43.2 \\
\hline 6 & PVP K30 & 4.6 & 4.6 & 4.6 & 4.6 & 4.6 & 4.6 & 4.6 & 4.6 & 4.6 \\
\hline 7 & Isopropyl alcohol & Q.S & Q.S & Q.S & Q.S & Q.S & Q.S & Q.S & Q.S & Q.S \\
\hline 8 & Magnesium stearate & 2.2 & 2.2 & 2.2 & 2.2 & 2.2 & 2.2 & 2.2 & 2.2 & 2.2 \\
\hline 9 & Total weight & 200 & 200 & 200 & 200 & 200 & 200 & 200 & 200 & 200 \\
\hline
\end{tabular}

SR: Sustained release, PVP: Polyvinylpyrrolidone, MCC: Microcrystalline cellulose

Table 2: Physical characteristics of levosulpiride SR matrix tablets

\begin{tabular}{llllll}
\hline Formulation code & $\begin{array}{l}\text { Angle of } \\
\left.\text { repose } \mathbf{(}^{\circ}\right)^{*}\end{array}$ & Loose bulk density $(\mathrm{g} / \mathrm{ml})^{*}$ & Tapped bulk density $(\mathrm{g} / \mathrm{ml})^{*}$ & Hausner ratio* & $\begin{array}{l}\text { Carr's } \\
\text { index }(\%) *\end{array}$ \\
\hline LF1 & $22.37 \pm 0.80$ & $0.734 \pm 0.01$ & $0.845 \pm 0.01$ & $1.15 \pm 0.01$ & $13.103 \pm 0.41$ \\
LF2 & $23.20 \pm 0.80$ & $0.713 \pm 0.02$ & $0.822 \pm 0.02$ & $1.15 \pm 0.01$ & $13.224 \pm 0.41$ \\
LF3 & $22.70 \pm 0.80$ & $0.726 \pm 0.02$ & $0.840 \pm 0.02$ & $1.15 \pm 0.01$ & $13.340 \pm 0.41$ \\
LF4 & $23.70 \pm 0.30$ & $0.721 \pm 0.01$ & $0.833 \pm 0.01$ & $1.16 \pm 0.01$ & $13.485 \pm 0.66$ \\
LF5 & $23.80 \pm 0.30$ & $0.732 \pm 0.01$ & $0.788 \pm 0.04$ & $1.16 \pm 0.01$ & $14.016 \pm 0.69$ \\
LF6 & $23.93 \pm 0.45$ & $0.739 \pm 0.01$ & $0.859 \pm 0.01$ & $1.16 \pm 0.00$ & $13.968 \pm 0.22$ \\
LF7 & $23.37 \pm 0.84$ & $0.646 \pm 0.02$ & $0.753 \pm 0.02$ & $1.17 \pm 0.01$ & $14.231 \pm 0.86$ \\
LF8 & $23.23 \pm 0.45$ & $0.676 \pm 0.04$ & $0.788 \pm 0.04$ & $1.17 \pm 0.01$ & $14.204 \pm 0.89$ \\
LF9 & $23.83 \pm 0.35$ & $0.677 \pm 0.03$ & - & $<1.25$ & $14.182 \pm 0.69$ \\
Standards & $20-30$ & - & - & & $12-16$ \\
\hline
\end{tabular}

${ }^{*}$ All the values were expressed as mean \pm SD, $n=3$, SR: Sustained release, SD: Standard deviation 


\section{Hardness test}

The hardness of the tablet was determined using Monsanto hardness tester $[7,9]$.

\section{Friability test}

A number of 6 tablets from each batch were examined for friability using Roche Friabilator (Tropical Equipment Pvt. Ltd. Mumbai, Maharashtra, India)and the equipment was run for 4 minutes at 25 revolutions per minute. The tablets were taken out, dedusted, and reweighted and percentage friability was calculated [7].

\section{Percent friability=Initial weight-Final weight $\times 100 /$ Initial weight}

\section{In vitro drug release studies}

In vitro dissolution [10-13] profile of each formulation was determined by the United States Pharmacopeia, $21^{\text {st }}$ revision (USP XXI) dissolution test apparatus (Apparatus II)method. The prepared levosulpiride tablets were placed inside the dissolution test apparatus filled with $900 \mathrm{ml}$ of phosphate buffer $\mathrm{pH}$ 6.8as dissolution medium. At predetermined time intervals, the sample was withdrawn, and the amount of levosulpiride released was determined by measuring the absorbance at $292 \mathrm{~nm}$ using a UV-visible spectrophotometer. From the absorbance values, the cumulative percentage drug release was calculated.

\section{Stability studies}

Stability studies were performed as per the International Conference on Harmonization (ICH) guidelines $[8,14]$ on formulation LF3. Selected formulation (LF3) was strip pack and stored at $25 \pm 2^{\circ} \mathrm{C}$ with $60 \pm 5 \% \mathrm{RH}$ and $40 \pm 2{ }^{\circ} \mathrm{C}$ with $75 \pm 5 \% \mathrm{RH}$ for 3 months. Samples were analyzed after storage for $1,2,3,6,9$, and 12 months. They were evaluated for appearance, hardness, friability, drug content, and drug release studies.

\section{RESULTS AND DISCUSSION}

\section{Formulation characteristics}

Levosulpiride SR tablets were prepared with different concentrations of chitosan, xanthan gum, and guar gum and were optimized by conducting various trials. The levosulpiride SR tablets were prepared by wet granulation technique. The drug release from the matrix tablets was found to be decrease with increase in drug polymer ratio.

\section{Drug excipient compatibility studies}

The IR spectra of pure levosulpiride as well as its mixture (1:1) with excipients showed 2966.6, 1619.3, 1589.0, 1339.2, and 916.2/cm wave number as major peaks. The results revealed no considerable changes in IR peak of levosulpiride and hence no interaction between drug and the excipients. DSC thermograms showed that no drug interaction occurred during the manufacturing process (Figs. 1-8).

\section{Precompression parameters}

The powders prepared for compression of SR tablets were evaluated for their flow properties; the results are shown in Table 2. The angle of repose was in the range of $22.37 \pm 0.80-23.93 \pm 0.45$ which indicates excellent flow of the powder for all formulations. The LBD of the powder formulation was in the range of $0.646 \pm 0.02-0.739 \pm 0.01 \mathrm{~g} / \mathrm{ml}$; the TBD was in the range of $0.753 \pm 0.02-0.859 \pm 0.01 \mathrm{~g} / \mathrm{ml}$, which indicates that the powder was not bulky. The Carr's index was found to be in the range of $13.10 \pm 0.41-14.23 \pm 0.86$, and the Hausner ratio was found to be in the range of $1.15 \pm 0.01-1.17 \pm 0.01$, indicating compressibility of the tablet blend is good. Hausner ratio was $<1.25$ for all batches indicating good flow properties. These values indicate that the prepared powders exhibited good flow properties.

\section{Post compression parameters}

The results of physicochemical characterizations are shown in Table 3. Thickness and diameter specifications may be set on an individual product basis. Excessive variation in the tablet thickness and diameter can result in problems with packaging as well as consumer acceptance. The thickness of matrix tablets was measured by vernier caliper and was ranged between $3.71 \pm 0.03$ and $3.87 \pm 0.06 \mathrm{~mm}$ for all formulation [15]. The weight variation for different formulations (LF1-LF9) was found to be $197.99 \pm 1.57-199.20 \pm 1.41$, showing satisfactory results as per the Indian Pharmacopoeia limit. The hardness of the matrix tablets was measured by Monsanto tester and was controlled between 7.26 \pm 0.06 and $7.96 \pm 0.06 \mathrm{~kg} / \mathrm{cm}^{2}$. This indicates good mechanical strength of tablet. The friability was below $1 \%$ for all the formulations, which is an indication of good mechanical resistance of the tablet. The percentage of drug content for LF1 to LF9 was found to be in between $98.47 \pm 0.15$ and $100.17 \pm 0.67 \%$ of levosulpiride; it complies with official specifications $[1,16]$.

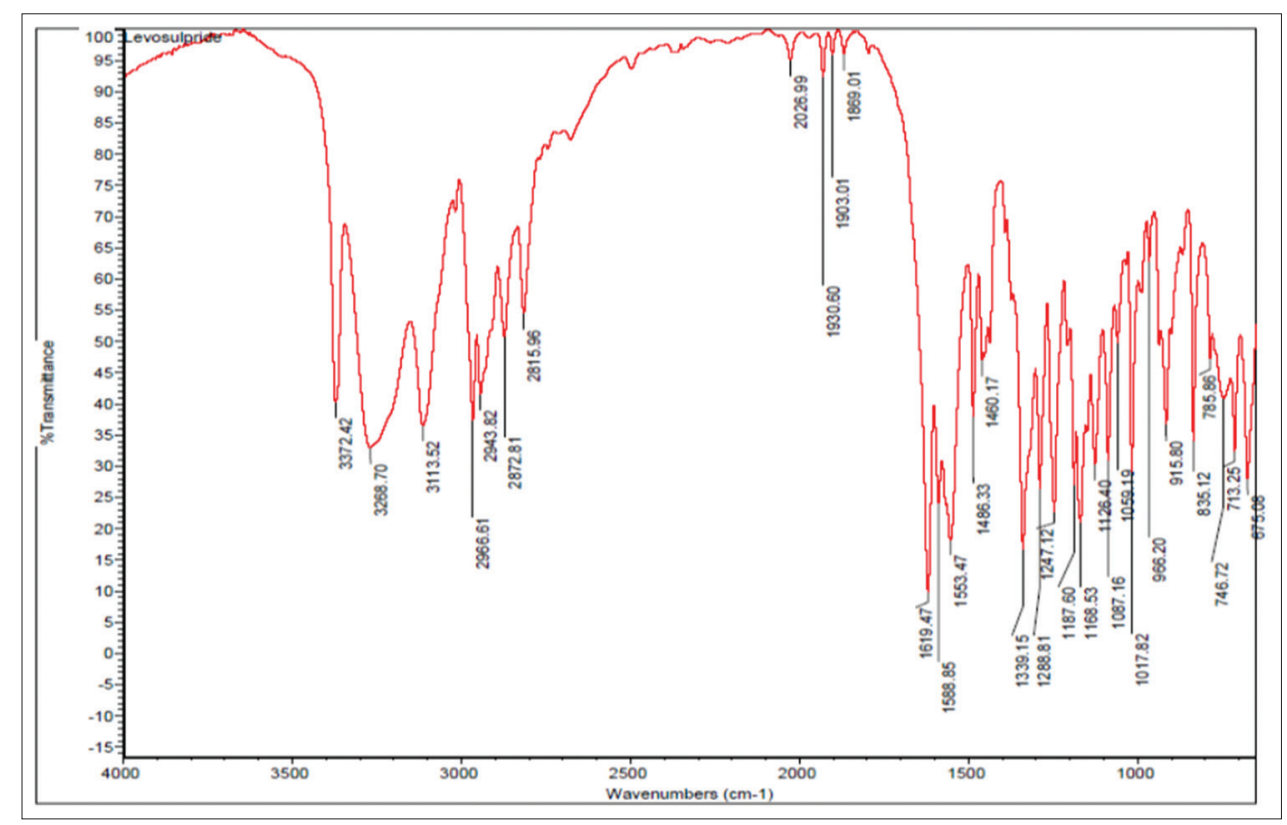

Fig. 1: Fourier transform infrared spectrum of levosulpiride 


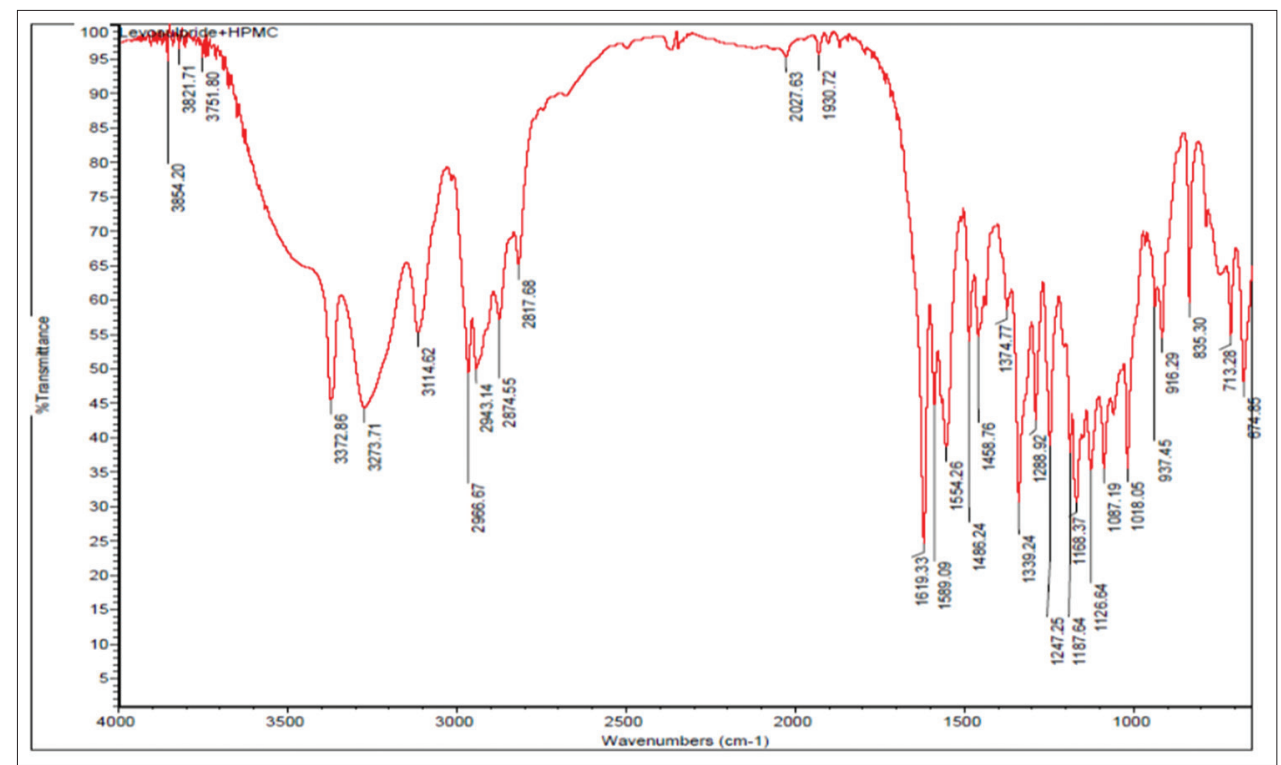

Fig. 2: Fourier transform infrared spectrum of levosulpiride with chitosan

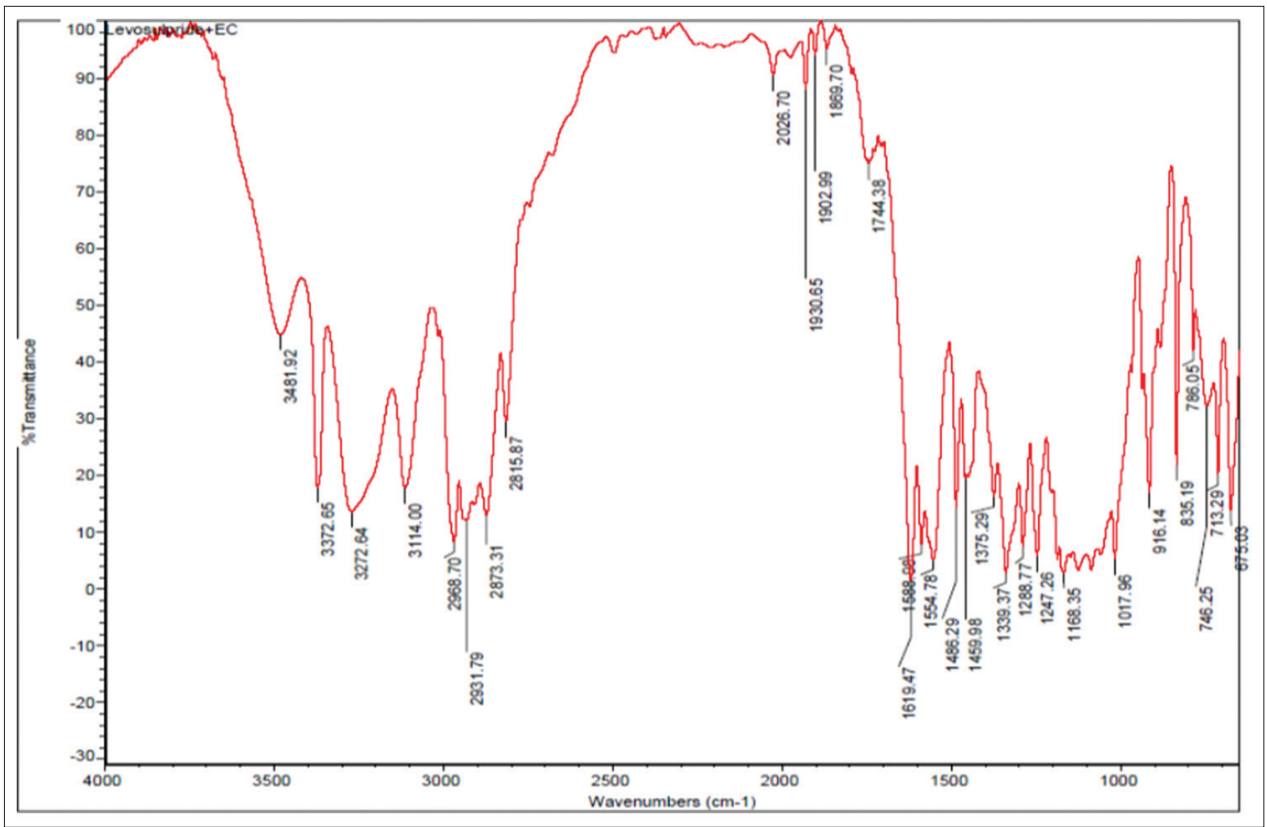

Fig. 3: Fourier transform infrared spectrum of levosulpiride with xanthan gum

Table 3: Physicochemical characteristics of levosulpiride SR matrix tablets

\begin{tabular}{|c|c|c|c|c|c|c|}
\hline \multirow[t]{2}{*}{ Formulation code } & \multicolumn{2}{|c|}{ Dimensions (mm) } & \multirow[t]{2}{*}{ Hardness $\left(\mathrm{kg} / \mathrm{cm}^{2}\right)$} & \multirow[t]{2}{*}{ Friability (\%) } & \multirow[t]{2}{*}{ Weight variation (mg) } & \multirow[t]{2}{*}{ Drug content $(\% \mathrm{w} / \mathrm{w})$} \\
\hline & Diameter & Thickness & & & & \\
\hline LF1 & $7.70 \pm 0.05$ & $3.87 \pm 0.06$ & $7.37 \pm 0.02$ & $0.278 \pm 0.00$ & $197.99 \pm 1.57$ & $98.47 \pm 0.15$ \\
\hline LF3 & $7.78 \pm 0.06$ & $3.87 \pm 0.04$ & $7.96 \pm 0.06$ & $0.288 \pm 0.00$ & $199.18 \pm 1.61$ & $99.45 \pm 0.30$ \\
\hline LF4 & $7.88 \pm 0.03$ & $3.78 \pm 0.03$ & $7.75 \pm 0.03$ & $0.288 \pm 0.00$ & $198.64 \pm 1.30$ & $99.64 \pm 0.53$ \\
\hline LF5 & $7.97 \pm 0.03$ & $3.72 \pm 0.04$ & $7.26 \pm 0.06$ & $0.288 \pm 0.00$ & $198.87 \pm 1.14$ & $100.13 \pm 0.24$ \\
\hline LF6 & $7.81 \pm 0.04$ & $3.78 \pm 0.03$ & $7.87 \pm 0.04$ & $0.283 \pm 0.00$ & $198.59 \pm 1.12$ & $99.48 \pm 0.35$ \\
\hline LF7 & $7.58 \pm 0.05$ & $3.71 \pm 0.03$ & $7.91 \pm 0.03$ & $0.284 \pm 0.00$ & $199.12 \pm 1.61$ & $100.10 \pm 0.21$ \\
\hline LF8 & $7.42 \pm 0.05$ & $3.71 \pm 0.04$ & $7.95 \pm 0.03$ & $0.286 \pm 0.00$ & $199.20 \pm 1.41$ & $100.17 \pm 0.67$ \\
\hline LF9 & $7.57 \pm 0.05$ & $3.72 \pm 0.04$ & $7.48 \pm 0.05$ & $0.273 \pm 0.00$ & $198.74 \pm 1.02$ & $98.47 \pm 0.39$ \\
\hline M1 & $7.72 \pm 0.03$ & $3.76 \pm 0.04$ & $7.94 \pm 0.04$ & $0.280 \pm 0.00$ & $198.94 \pm 1.61$ & $100.08 \pm 0.58$ \\
\hline Standards & - & - & $4-8$ & $<1$ & \pm 7.5 & $98-102$ \\
\hline
\end{tabular}

All the values were expressed as mean \pm SD, $n=3$, SR: Sustained release, SD: Standard deviation 


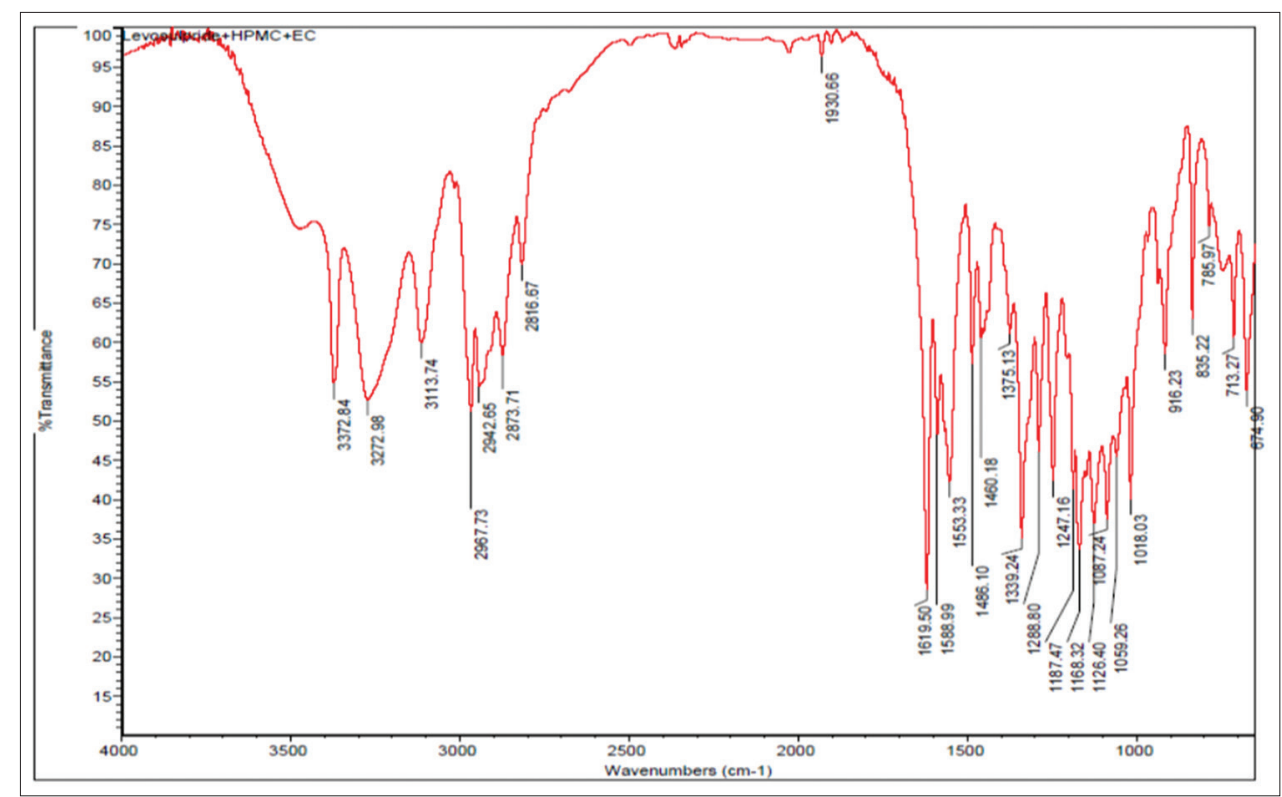

Fig. 4: Fourier transform infrared spectrum of levosulpiride with guar gum

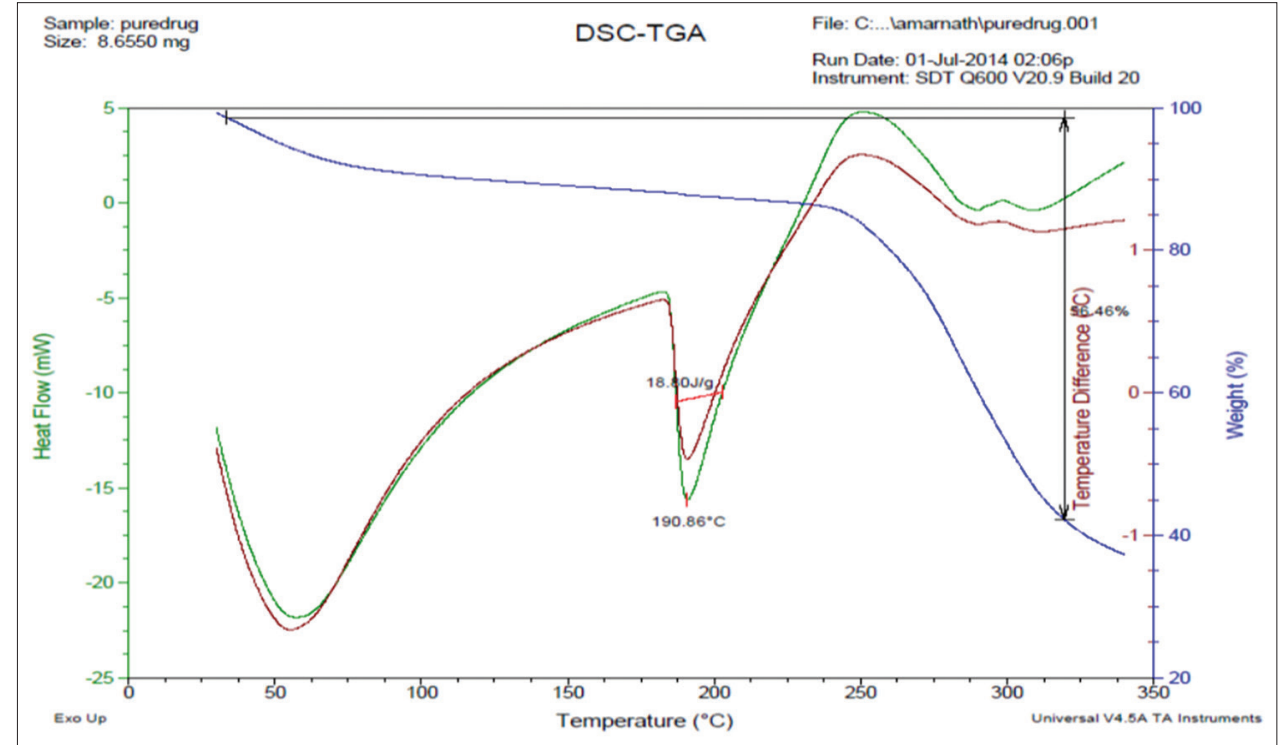

Fig. 5: Differential scanning calorimetry thermal analysis of levosulpiride

Table 4: Stability studies of levosulpiride SR matrix tablets LF3

\begin{tabular}{llllll}
\hline Stability chamber & $\begin{array}{l}\text { Time } \\
\text { (months) }\end{array}$ & Appearance & Hardness $\mathbf{( k g / \mathbf { c m } ^ { 2 } \text { ) }}$ & Friability (\%) & Drug content (\%) \\
& & & \\
\hline $25 \pm 2^{\circ} \mathrm{C}$ with $60 \pm 5 \% \mathrm{RH}$ & Initial & White & $7.96 \pm 0.06$ & $0.288 \pm 0.00$ & $99.45 \pm 0.30$ \\
& 1 & No change & $7.93 \pm 0.08$ & $0.286 \pm 0.00$ & $99.41 \pm 0.35$ \\
& 2 & No change & $7.90 \pm 0.07$ & $0.283 \pm 0.00$ & $99.38 \pm 0.27$ \\
& 3 & No change & $7.86 \pm 0.08$ & $0.281 \pm 0.00$ & $99.35 \pm 0.36$ \\
& 6 & No change & $7.83 \pm 0.05$ & $0.279 \pm 0.00$ & $99.31 \pm 0.29$ \\
& 9 & No change & $7.83 \pm 0.06$ & $0.274 \pm 0.00$ & $99.28 \pm 0.21$ \\
& 12 & No change & $7.82 \pm 0.07$ & $0.271 \pm 0.00$ & $99.25 \pm 0.65$ \\
\hline
\end{tabular}

All the values were expressed as mean \pm SD, $n=3$, SR: Sustained release, SD: Standard deviation

In vitro drug release studies

In vitro dissolution study was carried out for all the formulations as well as the marketed formulation (M1) using USPXXI dissolution test apparatus [6]. The drug release from the matrix tablets was found to be decrease with increase in drug polymer ratio. The drug released from formulation LF1 to LF3 containing chitosan at 3 concentration levels of $25 \%, 50 \%$, and $75 \%$ were found to be $95.53 \pm 0.89,95.14 \pm 1.59$, and $94.98 \pm 1.39 \%$ for levosulpiride at the end of $10^{\text {th }}, 11^{\text {th }}$, and $12^{\text {th }} \mathrm{hrs}$, respectively. The drug released from formulation LF4 to LF6 containing Xanthan gum at 3 concentration levels of $25 \%, 50 \%$, and $75 \%$ were 


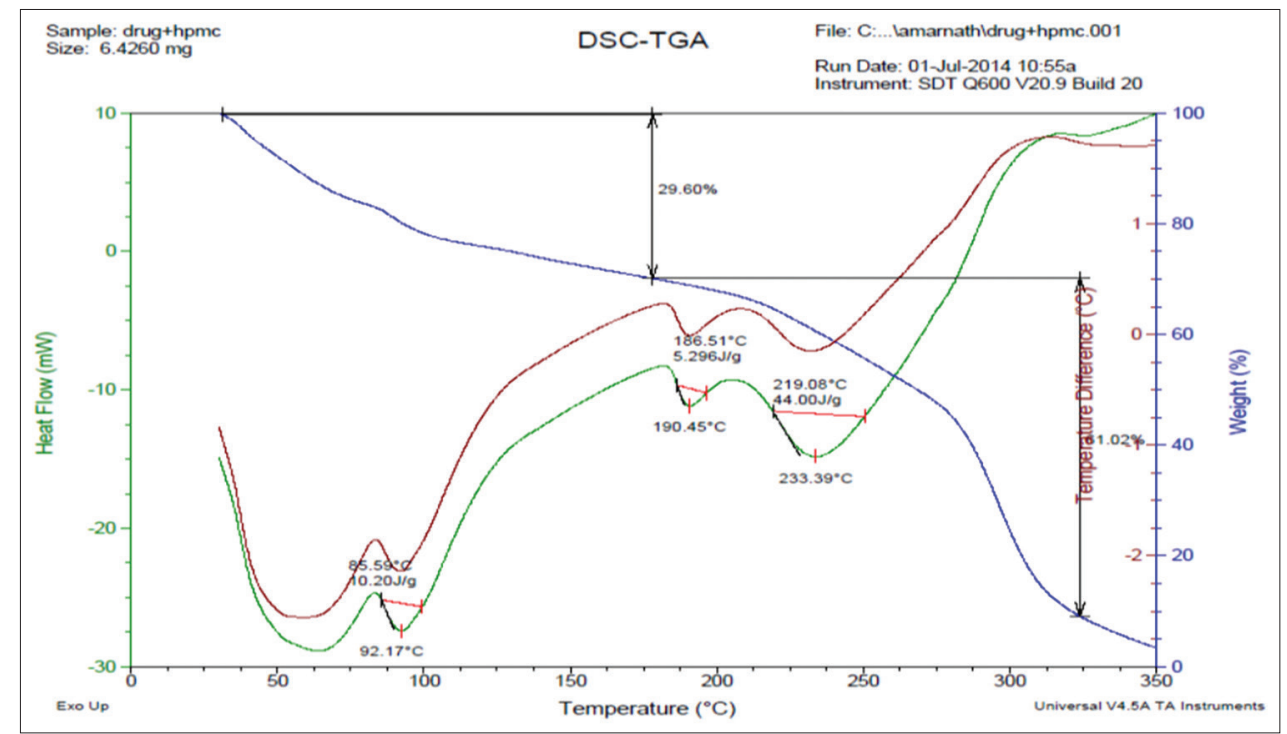

Fig. 6: Differential scanning calorimetry thermal analysis of levosulpiride with chitosan

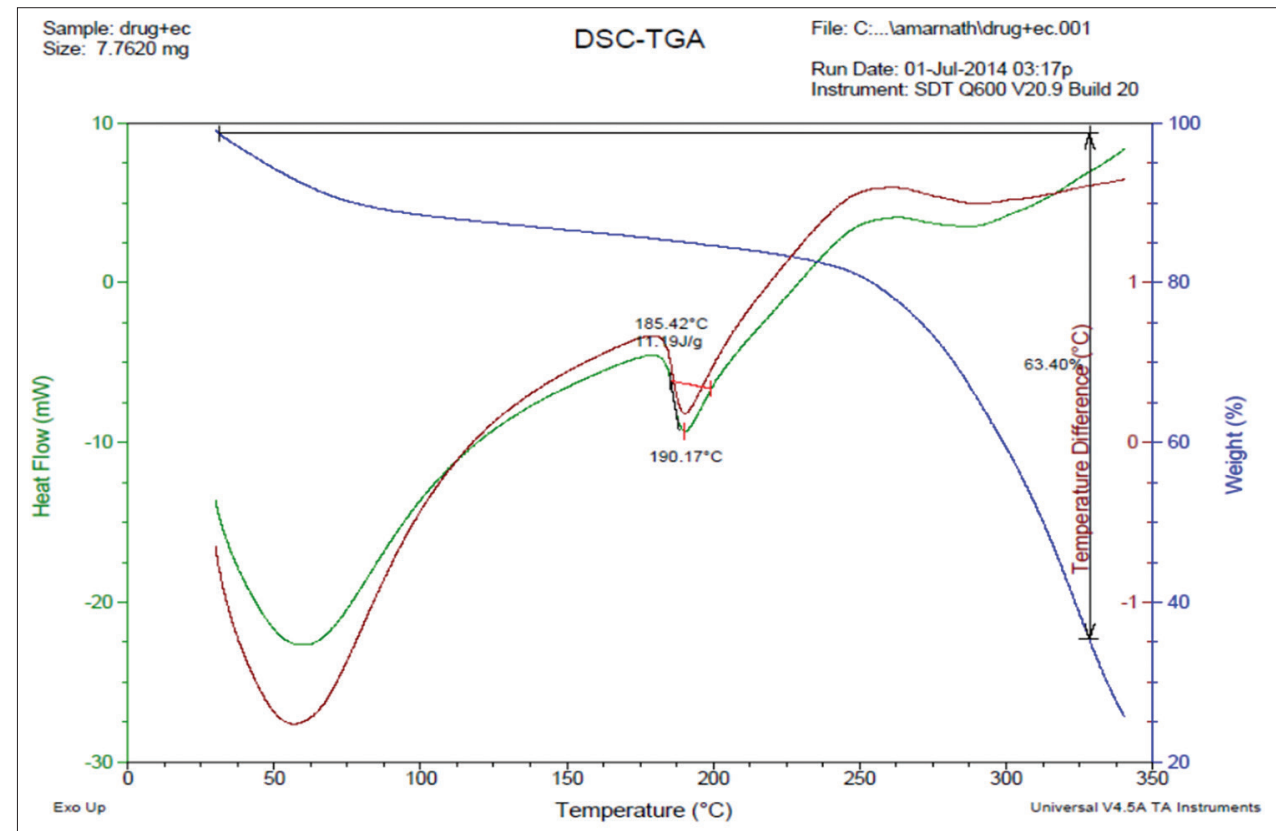

Fig. 7: Differential scanning calorimetry thermal analysis of levosulpiride with xanthan gum

Table 5: Stability studies of levosulpiride SR matrix tablets LF3

\begin{tabular}{|c|c|c|c|c|c|c|}
\hline Stability chamber & $\begin{array}{l}\text { Time } \\
\text { (months) }\end{array}$ & Appearance & Hardness $\left(\mathrm{kg} / \mathrm{cm}^{2}\right)$ & Friability (\%) & Drug content (\%) & $\%$ Drug release \\
\hline \multirow[t]{6}{*}{$40 \pm 2^{\circ} \mathrm{C}$ with $75 \pm 5 \% \mathrm{RH}$} & Initial & White & $7.96 \pm 0.06$ & $0.288 \pm 0.00$ & $99.45 \pm 0.30$ & $94.98 \pm 1.39$ \\
\hline & 1 & No change & $7.94 \pm 0.10$ & $0.285 \pm 0.42$ & $99.43 \pm 0.67$ & $94.47 \pm 0.46$ \\
\hline & 2 & No change & $7.91 \pm 0.28$ & $0.280 \pm 0.75$ & $99.40 \pm 0.81$ & $94.39 \pm 0.92$ \\
\hline & 3 & No change & $7.87 \pm 0.53$ & $0.278 \pm 0.32$ & $99.37 \pm 0.26$ & $94.30 \pm 0.23$ \\
\hline & 6 & No change & $7.86 \pm 0.65$ & $0.275 \pm 0.75$ & $99.35 \pm 0.78$ & $94.28 \pm 0.54$ \\
\hline & 9 & No change & $7.85 \pm 0.24$ & $0.274 \pm 0.65$ & $99.33 \pm 0.36$ & $94.27 \pm 0.85$ \\
\hline
\end{tabular}

All the values were expressed as mean \pm SD, $n=3$, SR: Sustained release, SD: Standard deviation

found to be $96.41 \pm 1.54,95.08 \pm 0.29$, and $94.83 \pm 1.42 \%$ for levosulpiride at the end of $9^{\text {th }}, 10^{\text {th }}$, and $11^{\text {th }}$ hrs, respectively.

The drug released from formulation LF7 to LF9 containing guar gum at 3 concentration levels of $25 \%, 50 \%$, and $75 \%$ were found to be $95.07 \pm 1.48 \%, 94.73 \pm 1.41$, and $94.40 \pm 2.78$ for levosulpiride at the end of $8^{\text {th }}, 9^{\text {th }}$, and $10^{\text {th }}$ hrs, respectively. In vitro release from the formulation LF3 was found to be $94.53 \%$. Hardness of LF3 was found to be $7.96 \pm 0.06 \mathrm{~kg} / \mathrm{cm}^{2}$. Higher hardness tablets contain a compact mass of polymer with relatively less pore, resulting in slower release. 


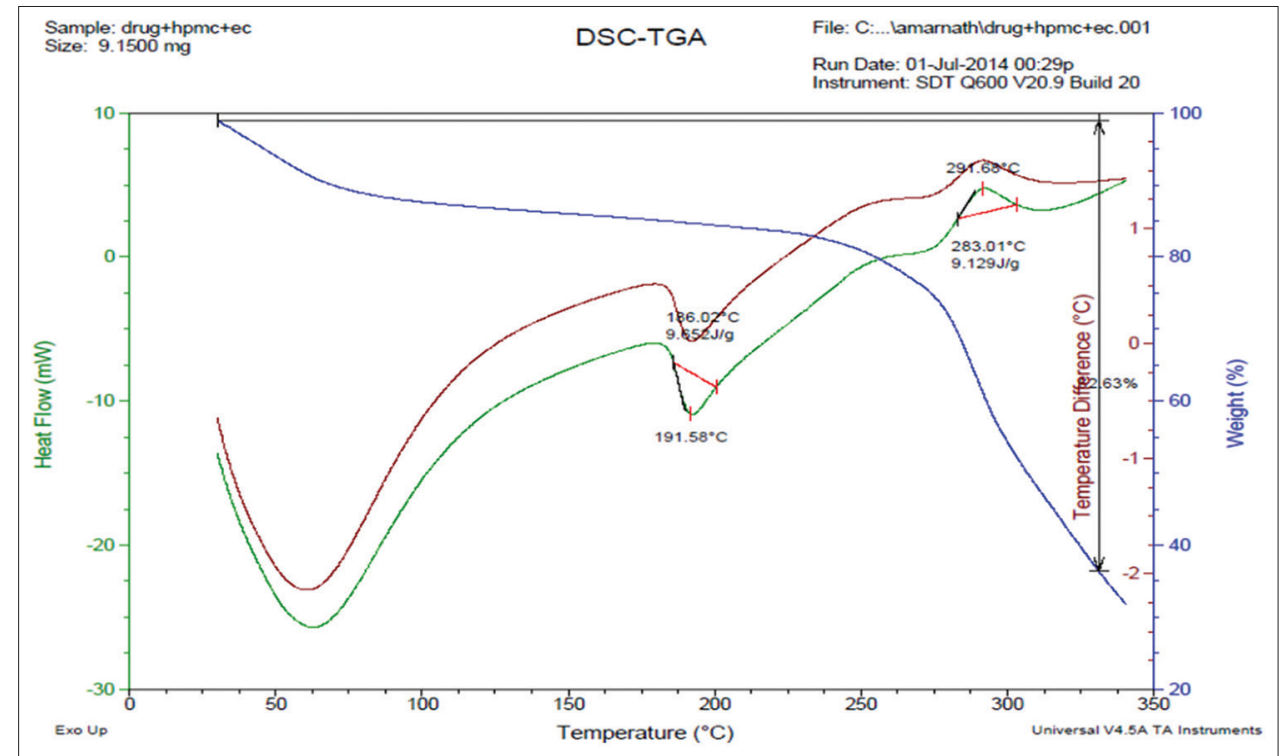

Fig. 8: Differential scanning calorimetry thermal analysis of levosulpiride with guar gum

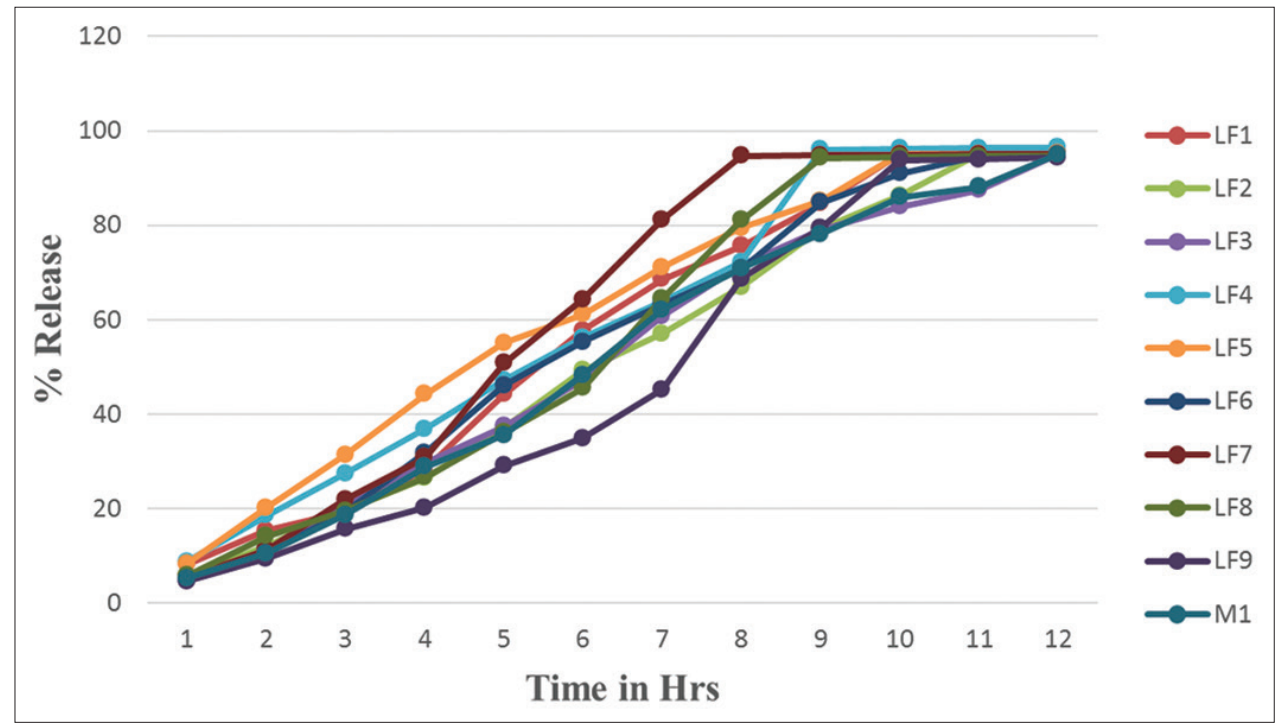

Fig. 9: In vitro drug release of levosulpiride sustained release matrix tablets

All other tested parameters of LF3 formulation were in the acceptable limits. Hence, the formulation LF3 was found to be better than other batch of formulations.

When the data were plotted according to zero-order equation, the formulations showed a fair linearity, with regression value between 0.983 and 0.994 . The correlation values of first order and Higuchi's equation of all the formulations were found to be 0.932-0.969 and 0.971-0.986. To confirm the super case II transport mechanism, the data were fit into Korsmeyer equation 0.987 to 0.998 [16] (Fig. 9).

\section{Stability studies}

Stability studies were performed as per the ICH guidelines on formulation LF3 [14]. The levosulpiride content was found to be within the acceptable limit. The cumulative drug release profile was found to be uniform. All other tested parameters (appearance, hardness, and friability) within the acceptable limit. The prepared formulation was found to be stable. Data of stability studies are shown in Tables 4 and 5

\section{CONCLUSION}

In this study, an effort was made to study SR levosulpiride tablets which can provide sustained drug release for up to $12 \mathrm{hrs}$. Levosulpiride SR tablets were formulated and evaluated. Levosulpiride SR tablets were prepared with different concentrations of chitosan, xanthan gum, and guar gum and were optimized by conducting various trials. The optimization procedure aided in the preparation of levosulpiride SR tablets with sustained drug release up to $12 \mathrm{hrs}$. The in vitro dissolution studies revealed that the formulated levosulpiride SR tablets released the desired concentration of the drug. Stability study as per the ICH guidelines was carried out and found to be stable. Hence, it may be concluded that the newly formulated levosulpiride SR tablets can be ideal and suitable for the treatment of psychiatric patients.

\section{REFERENCES}

1. Ansel HC, Allen LV, Popovich NG. Pharmaceutical Dosage Forms and Drug Delivery System. $4^{\text {th }}$ ed. New Delhi: Lippincott Williams and Wilkins; 2009. p. 227-74. 
2. Aulton ME. Pharmaceutics: The Design and Manufacture of Medicine. $3^{\text {rd }}$ ed. New York: Churchill Livingstone; 2007. p. 355-9, 483-98.

3. O’Niel MJ. The Merck Index. $12^{\text {th }}$ ed. New Jersey: Merck \& Co.; 1996. p. 9163.

4. Hardman JG, Limbird LE, editors. Goodman and Gilman's the Pharmacological Basis of Therapeutics. $10^{\text {th }}$ ed. New York: McGraw Hill; 2001. p. 1349-59.

5. Reynolds JE. Martindale - The Extra Pharmacopaeia. $13^{\text {th }}$ ed. London: The Pharmaceutical Press; 1993. p. 615.

6. Tanwar SS. Formulation and evaluation of sustained release matrix tablets of levosulpiride. Res J Pharm Biol Chem Sci 2013;4(2):1326-35.

7. Anonymous. Indian Pharmacopoeia. Vol. I, II and III. Ghaziabad, India: Government of India Ministry of Health and Family Welfare, The Indian Pharmacopoeia Commission; 2007. p. 142-83, 1276-85.

8. Carstensen JT, Rhodes CT. Drug Stability Principles and Practices. $3^{\text {rd }}$ ed. New York: Marcel Dekker, Inc.; 2008. p. 415-81.

9. Nazir I, Abbas J, Asad M, Bashir S, Rasul A, Ahmad N, et al. Formulation and in vitro evaluation of orodispersible tablet of levosulpiride. J Pharm Cosmet Sci 2013;1(4):53-6.

10. Brahmbhatt DD, Patel MB, Patel JC. Development and validation for estimation of levosulpiride by area under curve and difference spectrophotometric method. Int J ChemTech Res 2012;4(3):945-50.
11. Maheswaran A, Padmavathy J, Nandhini V, Saravanan D, Angel P. Formulation and evaluation of floating oral in situ gel of diltiazam hydrochloride. Int J Appl Pharm 2017;9(1):50-3.

12. Husen PM. Design and evaluation of controlled release matrix tablets of metoclopramide hydrochloride using hydrophilic polymers. Int $\mathrm{J}$ Curr Pharm Res 2012;4(3):64-9.

13. Kumar PS, Arivuchelvan A, Jagadeeswaran A, Subramanian N, Kumar CS. Formulation, optimization and evaluation of enrofloxacin solid lipid nanoparticles for sustained oral delivery. Asian J Pharm Clin Res 2015;8(1):231-6.

14. International Conference on Harmonization (ICH). Harmonized Tripartite Guideline for Stability Testing of New Drugs Substances and Products Q1A (R2). Rockville, MD: United States Pharmacopoeial Convention, Inc.; 2003. p. 6.

15. Albadry AA, Wedad K Ali, Fouad A Alsaady. Formulation and evaluation of prochloperazinemaleate sustained release floating tablets. Int J Pharm Pharm Sci 2017;9:89-98.

16. Thorat R, Patil P, Aage R, Puranik P, Virajselve. Formulation development and evaluation of venlafaxine $\mathrm{HCl}$ sustained release matrix tablets. Int J Pharm Pharm Sci 2013;5:757-65. 